\title{
Pendekatan Feminist Communication Theory pada Cybercommunity "Cerdas Nonton Televisi”
}

\author{
Ellys Lestari Pambayun Perguruan Tinggi Ilmu Al-Qur'an (PTIQ) Jakarta \\ ellyspambayun@gmail.com
}

\begin{abstract}
ABSTRAK
Penelitian tentang Pendekatan Feminist Communication Theory pada Cybercommunity "Wacana Cerdas Menonton Televisi" di internet berasal dari pengamatan tentang fenomena aktivitas percakapan para perempuan di e-forum Cerdas Nonton Televisi di internet yang memuat kondisi pertelevisian Indonesia di mana di tuang ini ditemukan masalah bahwa internet dengan facebook nya telah membangun suatu hubungan dan wacana para anggotanya secara terbuka, lugas, dan kritis, tanpa melihat status, gender, ekonomi, sosial, agama, dan gaya hidup tentang krisis televisi tanah air yang masih memiliki banyak masalah, baik pada penyiar, produser maupun berita atau program-programnya. Teori yang digunakan adalah paradigma kritis dengan salah satu variannya yaitu feminist communication theory yang bertujuan untuk melihat representasi perempuan di ruang publik yang menyuarakan atau mengkomunikasikan semua aspirasi, rasa keadilan, dan keberadaan mereka.

Tujuan penelitian adalah untuk menganalisis cybercommunity perempuan di e-forum "Cerdas Nonton Televisi" yang menyuarakan atau mewacanakan permasalahan pertelevisian Indonesia. Secara metodologis, penelitian ini menggunakan metode netnografi untuk melihat aktivitas budaya komunitas maya perempuan dalam bentuk percakapan di internet. Hasil pengamatan ini memberikan deskripsi bahwa para perempuan dalam e-forum Cerdas Nonton Televisi (CNT) ini telah berupaya mengoptimalisasikan ruang CNT untuk berkomunikasi atau bersuara kritis bagi terciptanya reformasi pertelevisian untuk lebih prokhalayak dan mencerdaskan bangsa. Namun, suara kritis perempuan masih lebih sedikit dibanding suara laki-laki dalam berwacana dalam ruang CNT ini. Selain, itu suara perempuan yang muncul lebih banyak pada hanya mengikuti status laki-laki, dibanding membuat status sendiri. Pada sisi substansi kritisisme perempuan pun cenderung menyiratkan keprihatinan secara emosioanal dibanding pada pengupayaan ke arah tranformasi secara nyata.
\end{abstract}

Kata Kunci: feminist, communication, cybercommunity, netnografi, cerdas, menonton,

\section{televisi. ABSTRACT}

Research on Feminist Theory Communication Approach on Cybercommunity "Cerdas Nonton Televisi"(CNT) on the Internet comes from the observation of the phenomenon of conversations activity of women in the e-forum CNT which contains conditions on Indonesian $\mathrm{TV}$ in the room where it was found that the problem with the internet (facebook) it has built up a relationship and discourse of its members openly, straightforwardly, and critical, regardless of status, gender, economic, social, religious, and lifestyle on television crisis that the country still has many problems, both on the broadcaster, producer and news or programs. The theory used is critical paradigm with one of its variants, namely feminist communication theory which aims to look at the representation of women in public spaces are voiced or communicate all the aspirations, sense of justice, and their whereabouts.

The research objective was to analyze cybercommunity women in e-forum "Smart Watch 
Television" are voiced or mewacanakan issues on Indonesian TV. Methodologically, this study using netnografi to see the virtual community cultural activity of women in the form of a conversation on the internet. These observations provide a description that the women of the e-forum Smart Watch Television (CNT) has sought to optimize this space to communicate or speak CNT critical for the creation of television for more prokhalayak reform and educate the nation. However, critical voices are still fewer female than a male voice in the discourse in this CNT space. In addition, the voice of women who appear more on just follow the status of men, rather than making their own status. On the substance of the criticism of women also tend to imply concern is emosional than at the insistence towards real transformation.

Keywords: feminist, communication, cybercommunity, netnografi, cerdas, menonton, televisi. 


\section{PENDAHULUAN}

\section{Latar Belakang Penelitian}

Kini, perempuan adalah bagian yang sangat signifikan keberadaanya di dunia maya. Mereka mengisi berbagai ruang maya sesuai kapasitas, kebutuhan, dan kepentingan mereka. Ungkapan pemikiran dan perasaan perempuan di ruang maya ini tidak hanya sebatas deskripsi ilmiah dengan mengeksplorasi berbagai teori dan perspektif yang mereka kuasai, namun melalui ruang facebook mereka berbagi keluhan, inspirasi, uneguneg, semangat bahkan kesempatan.

Kaitannya perempuan yang mengisi ruang facebook ini peneliti ingin secara khusus menyoroti para perempuan yang membangun wacana kritis tentang norma dan perubahan sosial di masyarakat Indonesia. Para perempuan ini tentu saja berasal dari daerah, budaya, agama, ideologi, pendidikan, ekonomi, status, bahkan gaya yang berbeda, namun yang menarik adalah dalam obrolan (wacana) yang saling terpisah, mereka membagi kritisisme yang relevan dan koheren satu sama lain, yaitu permasalahan pertelevisian di Indonesia yang semakin karut marut.Wacana yang terbangun dari suatu grup di facebook ini bernama "Cerdas Nonton Televisi" yang digagas seorang dosen dari Fakultas Ilmu Komunikasi Universitas Padjadjaran yang berjuluk Padekan Selamanya. Jadi para cybercommunity, istilah komunitas di dunia maya ini menurut peneliti aktivitas atau tindakan tutur atau wacana yang dibangun mereka mengindikasikan sebuah keprihatinan yang nyata dari semakin tersaruk-saruknya kondisi pertelevisian di abad teknologi informasi dan komunikasi, khususnya pola dan budaya menonton para audiensnya yang dinilai semakin tidak cerdas.

Grup "Cerdas Nonton Televisi” di facebook ini sebenarnya anggota atau komunitasnya terdiri dari laki-laki dan perempuan. Namun, peneliti lebih tertarik meneliti cara berwacana perempuan dengan tujuan untuk melihat dan menganalisis suara-suara kritis mereka terhadap pertelevisian Indonesia. Meskipun. para perempuan ini membagi "suara" di bulan Januari lalu, yang meski bukan hal baru, namun wacana mereka menggarisbawahi satu persoalan besar yang sama, wajah pertelevisian Indonesia, dan itulah yang membuat wacana mereka menjadi menarik dan penting untuk diangkat menjadi fokus kajian ini.

\section{Rumusan Masalah}

Bagaimana para perempuan sebagai cybercommunity di Grup FB "Cerdas Nonton Televisi" di internet menyuarakan dan mewacanakan permasalahan pertelevisian Indonesia secara kritis.

\section{Tujuan Khusus Penelitian}

Untuk menganalisis perempuan sebagai cybercommunity di Grup FB "Cerdas Nonton Televisi" di internet yang menyuarakan atau mewacanakan permasalahan pertelevisian Indonesia secara kritis. 


\section{TINJAUAN PUSTAKA}

Penelitian tentang netnografi ini didasrkan pada beberapa penelitian terdahulu diantaranya yang berjudul "Perbedaan Interaksi Antara Anggota Laki-Laki dan Perempuan Dalam Diskusi Online (Studi Netnografi pada Situs DetikForum)" tahun 2011 hasil penelitian Widatul Muhlishah dari jurusan Komunikasi Fisip Universitas Brawijaya yang mengungkapkan bahwa perbedaan interaksi antaraDetikers laki-laki dan Detikers perempuan yang jelas terlihat adalah bahwa dalam forum diskusi yaitu perempuan lebih memilih topik yang bersifat hiburan, kurang partisipatif dan interaktif, gaya komunikasi feminin,dan lebih santun. Sedangkan lakilaki lebih memilih topik informatif, partisipatif dan interaktif, gaya komunikasi maskulin, dan seringkali melanggar aturan komunikasi. Namun, kesamaannya adalak keduanya menggunakan bahasa slang dan emoticon untuk berinteraksi didetikForum. Selain itu, penelitian yang bertema "Persepsi Audience Terhadap Tokoh Ariel Noah Dalam Iklan TVC Vaseline for Men (Studi Netnografi Ariel Noah Dalam Ikaln Vaseline Man)" tahun 2014 yang dilaporkan Julio Reuneker dari Jurusan Ilmu Komunikasi Fisip Universitas Atmajaya Yogyakarta yaitu adalah bahwa perempuan lebih memilih Ariel sebagai model atau bintang iklan vaseline mankarena ganteng dan menarik, sedangkan laki-laki tidak setuju karena Ariel dianggap salah seorang tokoh yang pernah memiliki kasus hukum.

\section{KERANGKA TEORI}

\section{Paradigma Kritis}

Analisis penelitian tentang Pendekatan Feminist Communication Theory Pada Cybercommunity "Cerdas Nonton Televisi" di internet ini menggunakan Paradigma Kritik (Critical Theory) secara ontologism, epistemologis, dan metodologis yang bertujuan untuk mencerahkan audiens melalui pengungkapan kondisi struktural terhadap eksistensi manusia, khususnya menelisik dan mempertanyakan mengapa kondisi ini sampai terjadi dan adakah distorsi atau ketidakadilan yang menerpa mereka saat ini merupakan upaya rekayasa. Pencerahan ini dapat memberikan kemungkinan terciptanya kekuatan motivasi untuk merangsang tindakan ke arah otonomi yang lebih besar dan pada strategi tindakan politik menuju tanggung jawab sosial (social responsibility) dan emansipasi.

\section{Pendekatan Feminist Communication Theory}

Salah satu mainstream teori kritis yang cenderung lebih memfokuskan pada masalah keberadaan komunikasi perempuan atau gender di ruang publik seperti FBchat atau grup "Cerdas Nonton Televisi" adalah feminist communication theory yang merupakan pendekatan atau konsep untuk memahami dan menjelaskan gender, menolak jawaban-jawaban dan asumsi-asumsi yang tidak masuk akal tentang keberadaan perempuan. Selain itu, menegaskan bahwa perempuan sangat perlu untuk mengubah struktur untuk melahirkan hubungan sosial baru dan kemasyarakatan yang adil. (Rakow dan Wackwitz, 2004: 6)

Kriteria yang menjadi kekuatan feminist communication theory (fct), dapat diidentifikasikan sebagai berikut: Pertama,fct merupakan suatu eksplanasi, artinya teori ini mencari hubungan antara konsep-konsep dan pengalaman hidup, antara observasi dan pengetahuan, dan antara pemikiran dan aksi. Misalnya, dalam konsep wacana perempuan di grup fb "Cerdas Nonton Televisi" melalui pendekatan feminist communication theory ini harus mengartiulasikan perspektif yang ada dalam fct, mulai dari cara mengkaji sampai menginterpretasikan 
pengalamanperempuandigrupFBiniyangmengalamaidanmenyadariadanyaketidakberesan dalam dunia pertelevisian Indonesia, baik secara individu maupun grup melalui pendekatanpendekatan komunikasi strategis dan signifikan dalam kehidupan sehari-hari mereka, selain itu menempatkan dan melawan struktur dan makna-makna yang membentuk identitas dan pengalaman perempuan (yang tidak sesuai dengan nilai dan ideologi gender) . Kedua,fct itu bersifat politis. Artinya, suara perempuan selama ini "dibungkam" atau "dianggap sepi" dalam berbagai cara, karena itu tindakan sederhana seperti "bersuara/berbicara" di FB grup " Cerdas Nonton Televisi" akan menjadi suatu tindakan politis bagi mereka seperti melakukan debat terbuka tentang televisi, mengeksplorasi unsur-unsur perbedaan gender dalam kehidupan pertelevisian, menyuarakan anti kekerasan dan diskriminasi terhadap perempuan di televisi, dan melakukan representasi dalam lingkup keperempuanan "televisi" secara communicative action maupun di media seperti di FB. Ketiga, feminist communication theoryitu bersifat polyvocal.Artinya "suara-suara" ini berasal dari berbagai interpretasi perempuan terhadap realitas televisi Indonesia yang mereka alami. Suara berasal dari suara-suara perempuan yang kritis. Dalam konsep cybercommunity melalui pendekatan feminist communication theory menghendaki tindakan partisipatif perempuan melek media untuk menyamakan "suara" melalui aplikasi berbagai perspektif, metode, bentuk-bentuk aksi, dan pelaksanaan forumforum diskusi yang aktif, interaktif, dan komprehensif dalam mencari solusi pertelevisian Indonesia. Terakhir,bersifat transformatif, artinya teori ini memberikan sumbangan sangat besar terhadap pertumbuhan intelektual dan spiritual melalui perspektif yang berbeda terhadap struktur masyarakat dan pengalaman perempuan. Melalui pendekatan feminist communication theory, aksi atau wacana perempuan "Cerdas Nonton Televisi" secara terusmenerus melakukan transformasi pemikiran dan menginspirasikan tindakan pada, baik individu maupun kelompok perempuan melalui prakitk-praktik komunikasi yang masuk akal dan pengungkapan realitas-realitas penyebab terjadinya karut marut dan krisis pertelevisian Indonesia.

Terdapat tiga tema besar dan penting dalam pendekatan feminist communication theory yang dapat diterapkan pada perempuan "Cerdas Menonton Televisi" di FB, yaitu perbedaan-perbedaan (differences), suara-suara (voices), dan representasi yang dapat dijabarkan sebagai berikut. Pertama,perbedaan-perbedaan (differences) menurut feminist communication theory bahwa bahasa, materi, dan sistem politik memapankan hubungan opresif di dalam dan di antara orientasi media (televisi) yang berimplikasi pada masalah agama, ras, etnis, gender, ekonomi, seksualitas, kelas, dan politik. Khusus dalam masalah media televisi , konsekuensi dari perbedaan-perbedaan yang kompleks tentang kehidupan sosial, politik, agama, ekonomi, ideologi, dan sebagainya ini harus memunculkan pertanyaan politis dan filosofis bagi perempuan dalam grup FB "Cerdas Nonton Televisi", yaitu pada hubungan antara gender dan perempuan yang melek media televisi ini. Intinya, pada problematika media televisi yang dikaitkan dengan asumsi identitas, solidaritas, dan stabilitas tentang "kategori perempuan" sebagai cybercommunity yang mengkritisi media televisi. Karena itu, agar solusi dapat terealisasi secara integratif dan komprehensif grup FB "Cerdas Nonton Televisi" harus mendorong adannya gerakan perempuan alternatif di wilayah-wilayah Indonesia yang terfokus pada masalah cerdas menonton televisi pada masyarakat. Dengan begitu akan terjawab berbagai tantangan perempuan tersebut. Dengan cerdas menonton televisi yang kritis, analitis, dan evaluatif diharapkan akan menjawab dan menyelesaikan persoalan krisis televisi dan pola-pola menonton yang salah dan buruk pada perempuan lainnya.

Kedua,suara-suara (voices) adalah suatu tindakan betapa pentingnya perempuan bersuara 
karena selama ini perempuan selalu dipersulit untuk mendapatkan akses pada forumforum komunikatif, baik secara antarpribadi, kelompok, organisasional, dan di media. Melalui wacana "Cerdas Menonton Televisi" di grup FB ini perempuan didorong secara intelektual dan spiritual untuk lebih aktif dan berani mengkomunikasikan kondisi politis, sosial, ideologi, budaya, gender dan sebagainya dalam konteks media televisi sehingga dapat didengar dan meraih respek yang semestinya dari pihak-pihak yang selama ini meremehkan mereka. Ketiga,representasi. Segala yang berkaitan dengan ide, gambaran, image, narasi, produk-produk keilmuan (kajian gender dan media) adalah representasi. Denga kata lain representasi ini adalah teks. Realitas dan eksistensi perempuan grup FB "Cerdas Nonton Televisi" dibangun atas keterkaitan teks-teks (teks perempuan). Perempuan diperlakukan secara closed text tanpa penafsiran sesuai problematika sosial jamannya. Pendekatan feminist communication theory dalam wacana "Cerdas Nonton Televisi" ini mendorong perempuan melek media untuk bisa menjadi open text sehingga representasi mereka dapat lebih jelas terbaca dan terposisikan sesuai kodrat dan eksistensinya atau potensinya di wilayah publik maupun privat. (Rachman, 1996: 189)

\section{METODOLOGI}

\section{Pendekatan Penelitian}

Penelitian dengan judul "Pendekatan Feminist Communication Theory Pada Cybercommunity "Wacana Cerdas Nonton Televisi" di internet ini menggunakan pendekatan penelitian kualitatif. Dalam penelitian yang fokusnya melihat chatting di face book (FBchat) ditujukan untuk membahas wacana para anggota atau cybercommunity di grup FB “Cerdas Nonton Televisi”.

\section{Metode Penelitian}

Penelitian ini menggunakan studi netnografi (online ethnography atau virtual ethnography), yang merupakan varian dari etnografi artinya suatu pencatatan di lapangan tentang gambaran budaya melalui percakapan orang lain dengan bantuan teknologi komunikasi dan internet sehingga muncul teknik-teknik baru.Netnografi atau disebut juga dipopulerkan oleh Robert Kozinets di tahun 1977 (Maulana,2009:97) tetap dipertahankan prinsip kedalaman dan keluasan informasi yang dihasilkan dengan 'masuknya' periset ke dalam sebuah setting kehidupan untuk menghasilkan begitu banyak deskripsi yang sangat tebal (thick descriptions) melalui catatan-catatan yang dibuat dari hasil menyelami sebuah permasalahan. Salah satu kerisauan akan hasil netnography adalah apabila komunitas online (cybercommunity) seperti para perempuan pada grup "Cerdas Nonton Televisi" di internet yang digunakan tidak mewakili keseluruhan khalayak sasaran yang dipelajari. Oleh karena itu, peneliti berusaha untuk mengombinasikan netnography dengan teknik-teknik lain yang dilakukan, baik secara online maupun offline.Multiple methode merupakan sebuah cara untuk triangulasi dari hasil riset. Metode ini memang sebuah prosedur yang umum dalam sebuah riset kualitatif.

\section{Tahap Pengumpulan Data}

Penelitian ini menggunakan tahap pengumpulan datanya melalui teknik netnografi, sebagai berikut:

-Online Participatory: Peneliti berpartisipasi menjadi anggota dalam sebuah mailing list "Cerdas Nonton Televisi" di internet dan ikut dalam diskusi aktif di dalamnya. 
-Online Observational: Membaca dan menyimpulkan catatan-catatan diskusi yang lalu dari e-forum Cerdas Nonton Televisi" yang dilakukan para anggota perempuan.

-Online Chatting:Melakukan wawancara dengan informan yang direkrut dari sebuah komunitas online (cybercommunity) yaitu para perempuan dan narasumber kompeten yang menjadi anggota grup diskusi atau wacana di "Cerdas Nonton Televisi".

\section{Teknik Penarikan Sampel}

Penelitian ini dengan menggunakan purposive sampling, yaitujenis sampling yang digunakan dalam situasi khusus yang memerlukan penilaian seorang ahli dalam pemilihan kasus dengan tujuan khusus menurut pandangannya. Purposive sampling merupakan penelitian eksploratoris atau penelitian lapangan atau situasi partisipatif lainnya. (Neuman, 1997:206) Teknik ini digunakan dengan alasan bahwa kasus e-forum CNT di antar perempuan ini bersifat khusus, unik, dan menginformasikan yang khas. Misalnya, peneliti memilih percakapan para perempuan di grup "Cerdas Nonton Televisi" di internet untuk mengkaji keunikan dan kekhususan dari wacana mereka tentang pertelevisian, informan atau narasumber yang sulit diraih karena keberadaannya yang khusus (di internet), dan untuk mengidentifikasi tipe-tipe khusus melalui investigasi mendalam untuk meraih pemahaman tipe-tipe percakapan atau wacana yang lebih mendalam.

\section{Subjek Penelitian}

Peneliti menetapkan bahwa subjek dari penelitian ini adalah para perempuan yang menjadi anggota e-forum "Cerdas Nonton Televisi" di internet yaitu DM (admin CNT),JRS seorang dosen di Bandung dan HD sebagai praktisi media, dan ANS (anggota KPID Jabar). Sedangkan data sekunder peneliti peroleh dari perpustakaan atau dari laporan-laporan peneliti terdahulu, internet, majalah, surat kabar, jurnal ilmiah, dan dokumentasi lainnya yang berkaitan dengan konteks penelitian komunikasi gender pada cybercommunity "Cerdas Nonton Televisi" di internet.

\section{Teknik Analisis Data}

Data yang terkumpul dijabarkan secara analisis tematik dan kultural untuk menganalisis permasalahan pokok atau tematis pada penelitian mengenai budaya dan pola percakapan atau wacana para perempuan yang menjadi anggota e-forum "Cerdas Nonton Televisi" di internet tentang permasalahan seputar pertelevisian di Indonesia.

\section{Teknik Keabsahan Data}

Penelitian kualitatif ini menggunakan triangulasi atau dikenal dengan istilah cek dan ricek yaitu pengecekkan data dengan menggunakan beragam sumber, teknik, dan waktu, yaitu antara anggota (perempuan) e-forum "Cerdas Nonton Televisi" di internet, akademisi, dan praktisi media.

\section{ANALISIS DAN PEMBAHASAN PENELITIAN}

Dalam penelitian kualitatif yang berjudul "Pendekatan Feminist Communication Theory pada Cybercommunity 'Cerdas Menonton Televisi'” (CNT) ini telah berhasil menghimpun 
data berupa wacana/teks dan informasi yang sangat berguna dari para pelaku e-forum CNT sebagai key informan yaitu JRS (Dosen di Bandung), HD (praktisi media), DM (Admin /CNT dan dosen), dan ANS (Anggota KPID Jabar) untuk mengungkap permasalahan penting tentang pertelevisian Indonesia, khususnya pemikiran, gaya komunikasi, ideologi, dan budaya para penonton atau audiens Indonesia dalam mengonsumsi program-program televisi.

\section{Pendekatan Feminist Communication Theory}

Dalam perspektif feminist communication theory (fct) dengan salah satu kriterianya yaitu eksplanasi, para informan perempuan (JRS dan HDF) mengungkapkan dalam konsep wacana para informan perempuan di grup fb "Cerdas Nonton Televisi" mereka berusaha mengartikulasikan perspektif yang menyatakan bahwa dalam forum CNT wacana perempuan belum begitu menonjol karena kaum laki-laki lebih dominan, pada konteks televisi dikatakan baru sekedar berfungsi sebagai komoditas dan perempuan adalah salah satu objek dari komoditas tersebut, dan televisi Indonesia sangat tergantung selera

\section{JRS (Subjek)}

\begin{tabular}{|l|l|}
\hline Observasi Online & Wawancara Online \\
\hline Dulu sy serta bbrp di antara kita salut dgn & Sebetulnya saya kurang menyimak tentang \\
stasiun TV ini... Andy F Noya dan bbrp lg & perempuan yang ada di forum tsb... mungkin \\
yg masih punya hati untuk mencerdaskan & krn yg muncul lebih dominan kaum adam. \\
bangsa ini! & bisa jadi krn perempuan belum merasa \\
& terlalu dijadikan komoditas pembahasan \\
& yang lebih fokus di forum ini walaupun jika \\
dicermati tayangan TV bbrp melakukan \\
'komoditasisasi' perempuan (wah gaya bhs \\
viki yaa...)
\end{tabular}

\section{H D (Subjek)}

\begin{tabular}{|l|l|}
\hline Observasi Online & Wawancara Online \\
\hline Pengalaman Suryadi tentang betapa & Televisi masih menjadi media edukasi massif \\
dahsyatnya media massa: Pagi2 aku ora- & yang kuat, tetapi saat ini kurang menjadi \\
ga jalan pagi, termasuk ke kawasan studio & ajang pembinaan karakter bangsa, tayangan- \\
Persari yang menjadi langgananku. Kepada & tayangan relatively loss (bergantung selera \\
petugas kebersihan kutanya,"Ini yang pun- & masyarakat, mungkin juga karena rezim \\
ya masih mbak mia (Camelia Malik) kan?" & rating dalam industri pertelevisian). Musim \\
dijawab, “Masih Pak". Trus, Pak Hary Capry & korea, semuanya korea minded tetapi tanpa \\
juga masih di sini/" Lantas, dijawab: "masih & upaya balancing yang signifikan. \\
lah tuh, gak tau juga tuh gimana ya, padahal & \\
mereka kan dah pisahan ya?". dalam hatiku, & \\
pastilah mereka tahu dari media, sbb kan & \\
gk mungkin sang bos melapor ke anak buah & \\
ttg perceraian mereka. Ruaaaar biasa media & \\
massa itu yah! & \\
\hline
\end{tabular}




\section{DM (Admin CNT)}

\begin{tabular}{|c|c|}
\hline Observasi Online & Wawancara Online \\
\hline $\begin{array}{l}22 \text { Juni 8:43 } \\
22 \text { Juni } 2013 \text { 8:43 } \\
\text { "Mari Kita Kritisi Media Televisi" } \\
\text { (Diskusi Media Watch, Tahun 2016) } \\
\text { Dalam menyajikan gambar-gambar terbagi } \\
\text { dua: (1) Library/Archieve, yaitu file gambar } \\
\text { yang statusnya "rawan", artinya tidak } \\
\text { sembarangan bisa ditayangkan begitu saja. } \\
\text { Alasan lain, jika gambar-gambar seperti } \\
\text { itu dikeluarkan, maka akan menimbulkan } \\
\text { "trauma mendalam" bagi yang melihatnya. } \\
\text { Contoh file gambar tentang kerusuhan } \\
\text { antar suku, korban bencana, tragedi yang } \\
\text { memilukan, dll. Pada gambar-gambar seperti } \\
\text { itu harus ditulis kata "FILE" atau "DOK", } \\
\text { untuk menunjukkan bahwa gambar tersebut } \\
\text { bukan peristiwa baru, melainkan peristiwa } \\
\text { lama yang sudah terjadi. (2) Stock Shot, } \\
\text { YAITU gambar file yang bisa dikeluarkan } \\
\text { setiap saat dan tidak mengandung resiko. }\end{array}$ & $\begin{array}{l}\text { Diskusi para perempuan di forum ini, lebih } \\
\text { banyak berkeluh kesah tentang dampak } \\
\text { negatif yang mungkin ditimbulkan akibat } \\
\text { tayangan televisi yang tidak baik. Dan yang } \\
\text { mereka khawatirkan adalah anak-anak } \\
\text { mereka. }\end{array}$ \\
\hline
\end{tabular}

\section{ANS (Pengamat Televisi/Anggota KPI Jabar)}

\begin{tabular}{|l|l|}
\hline Observasi Online & Wawancara Online \\
\hline $\begin{array}{l}\text { Ihh kok colek saya mlulu, Pa dekan? Namun } \\
\text { saya juga sepakat penyebutan itu tetap kon- } \\
\text { tekstual. Hanya sekedar labeling, mungkin }\end{array}$ & $\begin{array}{l}\text { Saya tidak terlalu memperhatikan gender } \\
\text { anggota forum karena facebook agak } \\
\text { anonym, walau ada avatarnya tapi sering itu } \\
\text { OK, namun jika fonem itu dikonstruksi se- } \\
\text { bagai nilai maka tetap harus sejajar dengan } \\
\text { maknanya. }\end{array}$ \\
bagi saya siapa yang menulis pendapatnya. \\
\hline
\end{tabular}

Analisis apakah forum Cerdas Nonton Televisi di internet ini bersifat politis (sebagai kriteria kedua dari pendekatan Feminist Communication Theory) atau tidak, dapat terungkap dari pemaparan para informan, baik perempuan (JRS dan HD) maupun admin (DM) dan penga-mat TV/anggota KPID (AN) dalam penelitian ini. Informan perempuan menyiratkan bahwa perempuan belum sepenuhnya tampil dalam wacana CNT ini, karena kesadaran mereka un-tuk dapat memanfaatkan forum CNT sebagai ruang publik yang dapat menyuarakan sikap dan pemikiran mereka. Namun, di sini secara jelas terungkap bahwa mereka secara pribadi sangat sepakat bila ruang CNT dapat dijadikan sebagai suatu upaya tindakan politis peremp-uan agar dapat lebih "speakout" dan tidak voiceless. Informan lain (admin) pun menyatakan bahwa forum CNT adalah forum yang dapat mengakomodasi perempuan untuk dapat secara terbuka melakukan debat tentang televisi, mengeksplorasi unsur-unsur perbedaan gender dalam kehidupan pertelevisian, menyuarakan anti kekerasan dan diskriminasi terhadap per-empuan di televisi, dan melakukan representasi dalam lingkup keperempuanan "televisi" secara communicative action maupun di media seperti di forum CNT ini. Namun, pihak KPID 
Jabar (AN) belum melihat ruang publik seperti forum CNT ini dijadikan sebagai artikulasi politik bagi indvidu maupun kelompok tertentu (khususnya perempuan).

\section{JRS (Subjek)}

\begin{tabular}{|l|l|}
\hline Observasi Online & Wawancara Online \\
\hline 13 Januari 19:57 & Bisa dimanfaatkan, tapi kan kenyataannya \\
Wahai insan media...pertaruhkan integritas & belum terasa seperti itu. \\
diri, integritas institusi, integritas & \\
pemirsamu! & \\
\hline
\end{tabular}

\section{H D (Subjek)}

\begin{tabular}{|l|l|}
\hline Observasi Online & Wawancara Online \\
\hline & Waduuuhh aku nggak mikir sampai \\
& sejauh itu....syukur kalau bisa seperti \\
& itu. Aku merasa yang penting adalah bisa \\
& mengemukakan pendapat di ruang publik. \\
& Kalau itu berdampak politis ya syukur.... \\
\hline
\end{tabular}

\section{DM (Admin CNT)}

\begin{tabular}{|c|c|}
\hline Observasi Online & Wawancara Online \\
\hline $\begin{array}{l}20 \text { Januari 7:56 } \\
\text { BeberaBeberapa Stasiun Televisi, hingga } \\
\text { saat ini masih menayangkan gambar- } \\
\text { gambar ketika Jakarta dikepung banjir hebat. } \\
\text { baik dalam wawancara maupun dalam } \\
\text { pemberitaannya. Padahal, kondisi Jakarta } \\
\text { sudah mulai "membaik. tp media selalu lupa } \\
\text { untuk mencantumkan kata "FILE" atau "DOK" } \\
\text { Saya kira, "prosedure" seperti ini ada pada } \\
\text { standar Jurnalisme Televisi di manapun, tapi } \\
\text { kenapa sering dilupakdilupakan oleh teman- } \\
\text { teman Produser pemberitaan kita... }\end{array}$ & $\begin{array}{l}\text { Alhamdulillah CNT bisa menjadi salah satu } \\
\text { media untuk menampung keluhan kaum } \\
\text { perempuan soal tayangan televisi }\end{array}$ \\
\hline
\end{tabular}

\section{H D (Subjek)}

\begin{tabular}{|l|l|}
\hline Observasi Online & Wawancara Online \\
\hline itulah enaknya dapat mandat untuk & \\
menetapkan dan menegakkan aturan & \\
menurut UU yang dibuatkan oleh lembaga & \\
legislatif yang dipilih lewat pemilu yang di- & \\
duga demokratis itu. Kecuali mandatnya & \\
diubah, melalui revisi sejumlah UU yang & \\
isinya disepakati seluruh umat, maka kami & \\
akan tetap melakukan tindakan "suka-suka" & \\
itu. Hayu, gabung atuh. Hehe.29 Maret pukul & \\
16:23 melalui seluler. Suka & \\
\hline
\end{tabular}


Dalam kriteria ketiga pendekatan fct yaitu polyvocal, para informan perempuan (JRS dan HDF) mengungkapkan hasil interpretasi mereka yang cukup kritis dengan menyatakan bahwa perempuan belum menonjol dalam bersuara, apalagi menyamakan suara di antara mereka, sehingga warna suara perempuan dalam menyoroti pertelevisian di Indonesia ini belum terlihat. Padahal, di antara perempuan yang menjadi komunitas CNT ini banyak yang berkomentar positif, konstruktif, dan kritis. Pihak admin dalam hasil wawancara dan observasi online ini tersirat menghendaki tindakan partisipatif perempuan melek media untuk menyamakan "suara" melalui aplikasi berbagai perspektif, metode, bentuk-bentuk aksi, dan pelaksanaan forum-forum diskusi yang aktif, interaktif, dan komprehensif dalam mencari solusi pertelevisian Indonesia melalui forum CNT ini.

\section{J R S (Subjek)}

\begin{tabular}{|l|l|}
\hline Observasi Online & Wawancara Online \\
\hline $\begin{array}{l}\text { Mungkin aturan yg lalu sudah tdk b'laku lg } \\
\text { bhw iklan rokok hanya boleh tayang di atas } \\
\text { pk. 21.00. Dan bisa jadi Hukum rimba lah } \\
\text { yg sekarang jadi patokan!... Smg kt diberi } \\
\text { petunjuk u Ada di Jln yg benar. }\end{array}$ & $\begin{array}{l}\text { yang saya belum berani bilang ada warna } \\
\text { memberikan pernyataan seperti itu perlu } \\
\text { analisis isi yang lebih detil dan cermat, bisa } \\
\text { jadi ini karena saya di forum ini sebatas } \\
\text { menyimak konten kurang terlalu concern } \\
\text { pada siapa yang menyampaikannya. Bahkan } \\
\text { saya hanya bisa nyebutin nama Ellys LP } \\
\text { perempuan yg aktif di forum ini. Memang } \\
\text { brp aktifis di forum ini sih? trus brp orang } \\
\text { perempuannya? eeeehhh malah balik nanya } \\
\text { yaa...Maaf! }\end{array}$ \\
\hline
\end{tabular}

\section{Helsi Dinafitri (Subjek)}

\begin{tabular}{|l|l|}
\hline Observasi Online & Wawancara Online \\
\hline & $\begin{array}{l}\text { Perempuan di grup CNT memang tidak } \\
\text { seaktif pria dalam memberikan komen- } \\
\text { komen. Tetapi, tentu saja kalau dia tampil } \\
\text { akan menarik perhatian, apalagi kalau } \\
\text { isinya jitu tentu akan mendapat perhatian } \\
\text { lebih. Mereka cukup faktual dan kritis dalam } \\
\text { mengangkat apa-apa yagn terjadi dalam } \\
\text { keseharian di dunia pertelevisian. Jelaslah, } \\
\text { mereka memberikan kritik konstruktif } \\
\text { ataupun melengkapi sudut pandang yang } \\
\text { sudah ada. }\end{array}$ \\
\hline
\end{tabular}




\section{DM (Admin CNT)}

\begin{tabular}{|c|c|}
\hline Observasi Online & Wawancara Online \\
\hline $\begin{array}{l}20 \text { Februari 18:21 } \\
\text { Apakah ada penjelasan yang bisa diterima } \\
\text { (selain bertujuan kampanye), jika saat ini } \\
\text { SCTV menayangkan sinetron seri "Kiamat } \\
\text { Makin Dekat" yang dibintangi oleh salah } \\
\text { seorang calon Cawagub Jabar. Media massa } \\
\text { mestinya menjadi garda terdepan dalam } \\
\text { mengusung demokratisasi. Andai saja itu } \\
\text { merupakan "pesanan" dari si Calon, wah ini } \\
\text { lebih berbahaya lagi. Mari kita kawal Pilkada } \\
\text { Jabar ini agar bersih, jujur, adil dan FAIR. } \\
\text { Semoga message ini terbaca oleh teman- } \\
\text { teman di SCTV, karena saya tahu di sana } \\
\text { banyak sekali orang yang CERDAS....!! }\end{array}$ & $\begin{array}{l}\text { Tentu saja menarik dan berbeda, karena } \\
\text { biasanyakan perasaan perempuan itu } \\
\text { halus dan cenderung jujur, sehigga apa } \\
\text { yang dikeluhkan mereka selama ini, boleh } \\
\text { jadi mewakili keluhan kaum perempuan } \\
\text { secara keseluruhan sebagai penikmat media } \\
\text { televisi. }\end{array}$ \\
\hline
\end{tabular}

\section{ANS (Pengamat Televisi/Anggota KPI Jabar)}

\begin{tabular}{|c|c|}
\hline Observasi Online & Wawancara Online \\
\hline $\begin{array}{l}\text { KOMISI PENYIARAN INDONESIA DAERAH } \\
\text { [KPID] JAWA BARAT } \\
\text { Publikasi } \\
\text { Kepada seluruh Lembaga Penyiaran di Jawa } \\
\text { Barat. } \\
\text { Sifat : Sangat Penting } \\
\text { Hal: Pengaturan Khusus Isi Siaran Pada Masa } \\
\text { Tenang Pilkada Gubernur Jawa Barat } \\
\text { Seperti diketahui, saat ini warga Jawa } \\
\text { Barat sedang menyelenggarakan proses } \\
\text { pemilihan Gubernur dan Wakil Gubernur. } \\
\text { Sesuai Keputusan KPU Propinsi Jawa Barat } \\
\text { Nomor 01/Kpts/KPU-Prov-011/VII/2012 } \\
\text { Tanggal 20 Juli 2012 tentang Tahapan, } \\
\text { Program, dan Penyelenggaraan Pemilihan } \\
\text { Gubernur dan Wakil Gubernur Jawa Barat } \\
\text { Tahun 2013, antara Hari KamisTanggal } 21 \\
\text { Februari 2013 hingga Hari Sabtu 23 Februari } \\
\text { 2013,dinyatakan sebagai MASA TENANG. }\end{array}$ & $\begin{array}{l}\text { Masyarakat pada masa pemilu dikondisikkan } \\
\text { untuk lebih tenang dan waspada pada } \\
\text { muatan-muatan media massa atau televise } \\
\text { yang provokatif dan tidak membuat chaos..... }\end{array}$ \\
\hline
\end{tabular}

Pengamatan terhadap komunitas perempuan dalam e-forum Cerdas Nonton Televisi secara terus-menerus melakukan transformasi pemikiran dan menginspirasikan tindakan pada, baik individu maupun kelompok perempuan seperti menghendaki perempuan terus bersuara kritis, memperjuangkan diri agar tidak menjadi komoditas dalam televisi, dapat selektif dalam mengcounter muatan-muatan negatif dalam tayangan televisi, dan mengupayakan agar pandanganpandangan perempuan melalui televisi lebih didengar. Pihak admin sangat sepakat bahwa perempuan memang harus terus berjuang bersama untuk dapat membendung arus muatan televisi, terutama yang negatif agar tidak merasuki kehidupan nyata mereka. 


\section{JRS (Subjek)}

\begin{tabular}{|c|c|c|}
\hline Observasi Online & & Wawancara Online \\
\hline $\begin{array}{l}\text { Menjadi reporter itu memang } \\
\text { tidak gampang! Selain } \\
\text { keberanian, rasa percaya } \\
\text { diri, dan kecerdasan juga } \\
\text { perlu hati untuk berempati } \\
\text { pada situasi yg tengah } \\
\text { dihadapi. Terus belajar dan } \\
\text { mengasah hati adalah kunci } \\
\text { keberhasilannya. }\end{array}$ & $\begin{array}{l}\text { Oh maaf. Judul2 program } \\
\text { selain smackdown, } \\
\text { ditindak oleh KPI Pusat. } \\
\text { Bukan KPID. }\end{array}$ & $\begin{array}{l}\text { Ini pendapat pribadi (krn kl } \\
\text { baca pertanyaan ini harusnya } \\
\text { yg jawab adminnya forum), } \\
\text { pertama: perempuan } \\
\text { untuk tidak } \text { lg dijadikan } \\
\text { komoditas tayangan } \\
\text { media apa pun, } \\
\text { perempuan sadar untuk mau } \\
\text { bersuara memperjuangkan } \\
\text { kemulyaannya } \\
\text { berbagai forum yg ada } \\
\text { termasuk CNT. }\end{array}$ \\
\hline
\end{tabular}

\section{H D (Subjek)}

\begin{tabular}{|c|c|}
\hline Observasi Online & Wawancara Online \\
\hline $\begin{array}{l}\text { HAJI MUHIDIN MENDADAK BAIK: } \\
\text { HARUSKAH KITA MEMBERANGUS DA'I? } \\
\text { (by: my hubby, Suryadi) } \\
\text { Kaget juga, tiba-tiba Haji Muhidin, pemeran } \\
\text { antagonis dalam Sinetron "Tukang Bubur } \\
\text { Naik Haji", mendadak baik. Padahal, selama } \\
\text { ini meski mengklaim diri "RW, Haji } 2 \mathrm{x} \text {, haji } \\
\text { mabrur", toh ia tetap saja kikir, iri, dengki, } \\
\text { pada putri semata wayangnya saja yang } \\
\text { sangat menyanginya dengan tulus, dia } \\
\text { bercuriga, cuma bisa lembut pada seorang } \\
\text { janda cantik yang ia ingin peristri..... }\end{array}$ & $\begin{array}{l}\text { Transformasi perempuan yang dikehendaki } \\
\text { oleh CNT melalui wacana pertelevisian ini } \\
\text { adalah } \\
\text { a. mengajak kaum perempuan untuk } \\
\text { meningkatkan concern-nya terhadap } \\
\text { dunia pertelevisian karena televisi telah } \\
\text { menjadi sarana edukasi yang massif } \\
\text { terutama di kalangan generasi muda baik } \\
\text { edukasi positif maupun negatif } \\
\text { b. mengajak perempuan melihat dari segala } \\
\text { sisi terhadap isu-isu yang diangkat } \\
\text { oleh pertelevisian ataupun yang tidak } \\
\text { diangkat. } \\
\text { c. menjadikan perempuan sebagai } \\
\text { sahabat industri pertelevisian dengan } \\
\text { mendengarkan insights mereka. }\end{array}$ \\
\hline
\end{tabular}

\section{H D (Subjek)}

\begin{tabular}{|l|l|}
\hline Observasi Online & Wawancara Online \\
\hline $\begin{array}{l}\text { Xixiixi Aaallll bangunn.....kumaha eta surat } \\
\text { nu kamari teh geuningan "dilecehkan".... } \\
\text { hadoohhh }\end{array}$ & $\begin{array}{l}\text { Paling tidak transformasi pengalaman yang } \\
\text { diperolehnya dalam keseharian mereka. } \\
\text { Bagaimana perilaku kaum perempuan dalam } \\
\text { menghadapi media televisi, bagaimana kisah } \\
\text { betapa sulitnya membendung arus informasi } \\
\text { yang tidak baik, yang ditularkan lewat media } \\
\text { televisi, dan bagaimana mereka merasa sulit } \\
\text { mengcounter pesan-pesan negatif akibat } \\
\text { tayangan televisi, dll. }\end{array}$ \\
\hline
\end{tabular}




\section{ANS (Pengamat Televisi/Anggota KPI Jabar)}

\begin{tabular}{|l|l|}
\hline Observasi Online & Wawancara Online \\
\hline Peringatan Tertulis 11 TV Perihal ILM & Jawaban idem dengan no.3 \\
"PT Djarum Edisi Bulan Ramadhan versi & \\
Merawat Orang Tua” & \\
www.kpi.go.id & \\
KPI Komisi Penyiaran Indonesia - Jadikan & \\
Penyiaran Indonesia yang Sehat, Bermanfaat, & \\
dan Bermartabat & \\
& \\
\hline
\end{tabular}

Analisisterhadapwacanaperempuandiforum “CerdasNontonTelevisi"diFB,inimenunjukkan adanya perbedaan-perbedaan (differences), suara-suara (voices), dan representasi dalam hal bahasa, materi, dan sistem politik memapankan hubungan opresif di dalam dan di antara orientasi media (televisi) yang berimplikasi pada masalah agama, ras, etnis, gender, ekonomi, seksualitas, kelas, dan politik. Misalnya, dalam bahasa dan materi saja perempuan seringkali disebut dengan sebutan-sebutan dan ditempatkan secara telak yang justru memperlemah posisi perempuan. Dalam materi contohnya, perempuan selalu dianggap sebagai kaum yang materialistis dengan menghalalkan berbagai cara untuk mencapai tujuannya tersebut, seperti denga merebut suami orang, berselingkuh dengan pejabat, menjadi objektivikasi berbagai produksi, dan sebagainya. Secara politis juga perempuan tidak ditampilkan sebagai subjek tapi objek dari sistem yang dikuasai laki-laki tersebut. Admin menawarkan solusi dalam forum CNT ini bahwa dalam masalah media televisi, konsekuensi dari perbedaan-perbedaan yang kompleks tentang kehidupan sosial, politik, agama, ekonomi, ideologi, dan sebagainya ini harus memunculkan pertanyaan politis dan filosofis bagi perempuan dalam grup FB "Cerdas Nonton Televisi", yaitu pada hubungan antara gender dan perempuan yang melek media televisi ini. Intinya, pada problematika media televisi yang dikaitkan dengan asumsi identitas, solidaritas, dan stabilitas tentang "kategori perempuan" sebagai cybercommunity yang mengkritisi media televisi. Karena itu, agar solusi dapat terealisasi secara integratif dan komprehensif grup FB “ Cerdas Nonton Televisi" harus mendorong adannya gerakan perempuan alternatif di wilayahwilayah Indonesia yang terfokus pada masalah pendidikan tentang media televisi agar tercapai kecerdasan menonton televisi pada masyarakat. Dengan begitu akan terjawab berbagai tantangan perempuan tersebut. Dengan cerdas menonton televisi yang kritis, analitis, dan evaluatif diharapkan akan menjawab dan menyelesaikan persoalan krisis televisi dan pola-pola menonton yang salah dan negatif pada perempuan Indonesia selama ini.

\section{JRS (Subjek)}

\begin{tabular}{|c|c|}
\hline Observasi Online & Wawancara Online \\
\hline $\begin{array}{l}\text { Andai Arita Gloria Zulkifli scr jumlah cukup } \\
\text { banyak, maka tidak perlu khawatir masa } \\
\text { depan bangsa ini.... } \\
\text { Apakah hrs spt itu cara interview, Najwa? } \\
\text { Siapa pun narasumbernya. Dongak dagumu, } \\
\text { intonasi dan aksen tanyamu! } \\
\text { Curhatan peserta un yg nulis di blog ttg ljun } \\
\text { yg butut, diwawancara Metro... Kalau dia } \\
\text { daftar Fikom, langsung aja terima, cerdas } \\
\text { dan cantik pula. }\end{array}$ & $\begin{array}{l}\text { Bahasa, materi, sistem politik dan apa } \\
\text { pun memang secara selintas orientasi } \\
\text { industrinyalah yg sangat menonjol, dan jika } \\
\text { perspektifnya adalah ekonomi biasanya } \\
\text { tidak lagi punya alasan untuk membuat } \\
\text { pertimbangan selain keuntungan yang } \\
\text { sebesar-besarnya. }\end{array}$ \\
\hline
\end{tabular}




\section{H D (Subjek)}

\begin{tabular}{|l|l|}
\hline Observasi Online & Wawancara Online \\
\hline $\begin{array}{l}\text { Ariel betapa pun kotornya dia sudah } \\
\text { menjalani hukum. Jauh lebih baik daripada } \\
\text { banyak koruptor di negeri ini. Apalagi } \\
\text { sekedar Jupe. Kalau ingin mengkritisi } \\
\text { keduanya lebih baik kritisi saja koruptor } \\
\text { yang sampai sekarang tak tersentuh.... }\end{array}$ & $\begin{array}{l}\text { Iya banget. Perempuan kerap menjadi } \\
\text { bancakan empuk pemberitaan kasus-kasus } \\
\text { korupsi, hukum, politik. Dalam berita, } \\
\text { sudah sangat jelas si laki-laki yang korupsi } \\
\text { tetapi televisi malah mengexpose wanita- } \\
\text { wanita simpanan -terlepas dikawinin } \\
\text { apa tidak- sampai para wanita tersebut } \\
\text { diuber-uber sampai over ekspose hingga } \\
\text { menenggelamkan sosok laki-laki yang korup } \\
\text { dan melekatkan kejahatan korupsi kepada } \\
\text { para wanita ........ }\end{array}$ \\
\hline
\end{tabular}

\section{DM (Admin CNT)}

\begin{tabular}{|l|l|}
\hline Observasi Online & Wawancara Online \\
\hline $\begin{array}{l}\text { 10 Januari 20:27 } \\
\text { wajahnyaa...cantik..! }\end{array}$ & $\begin{array}{l}\text { Perempuan sebagai pengkonsumsi televisi, } \\
\text { saya kira telah menjadi bagian penting dari } \\
\text { keberadaan televisi itu sendiri. Bayangkan } \\
\text { sebagian besar yang mengonsumsi } \\
\text { tayangan2 televisi itu adalah kaum ibu } \\
\text { (khususnya di pedesaan dan dari golongan } \\
\text { pendidikan rendah). Dan justru kaum ibu } \\
\text { inilah yang kemudian akan menularkan } \\
\text { "pengetahuan dangkal" yang diperolehnya } \\
\text { dari media televisi kepada anak-anaknya. } \\
\text { Oleh karena itu, kamu ibulah yang harus } \\
\text { mendapat pendidikan literasi media televisi, } \\
\text { bagaimana agar mereka (kaum perempuan), } \\
\text { hanya mengkonsumsi tanangan2 yang } \\
\text { berkualitas dan memiliki nilai pendidikan } \\
\text { yang baik. }\end{array}$ \\
\hline
\end{tabular}

\section{DM (Admin CNT)}

\begin{tabular}{|c|c|}
\hline Observasi Online & Wawancara Online \\
\hline 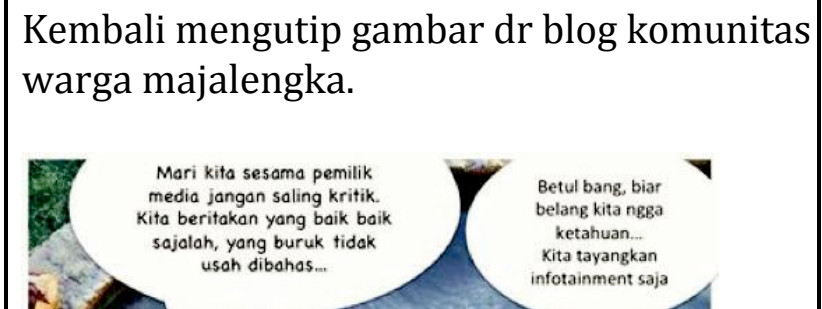 & $\begin{array}{l}\text { Saya tidak tahu motif admin terhadap agenda } \\
\text { politik terentu. Saya sendiri tidak pernah } \\
\text { mengkhususkan pada agenda tertentu, } \\
\text { kecuali menjadikan televisi sebagai ruang } \\
\text { publik yang dapat diakses seluruh warga } \\
\text { negara. }\end{array}$ \\
\hline
\end{tabular}


Para informan sepakat bahwa e-forum Cerdas Nonton Televisi dapat menjadi sarana "menyuarakan" aspirasi perempuan, karena suara-suara (voices) perempuan sangat penting "berkumandang" di tengah dominasi suara laki-laki di ruang publik. Suara perempuan tentu saja berbeda dengan suara laki-laki dari perspektif gender, di mana perempuan bersuara melalui emosionalitas mereka terhadap problematika televisi Indonesia dan mengalami banyak kesulitasn bersura di ruang publik karena banyak akses yang tidak terbuka pada mereka. Karena itu, baik para informan perempuan maupun admin dan pihak KPID/ pengamat televise beranggapan bahwa melalui wacana "Cerdas Nonton Televisi" di grup FB ini perempuan bisa terpacu secara intelektual dan spiritual untuk lebih aktif dan progresif mengkomunikasikan kondisi politis, sosial, ideologi, budaya, gender dan sebagainya dalam konteks media televisi sehingga suara mereka dapat didengar, setara denga laki-laki, dan meruntuhkan pandangan tentang keberadaan perempuan sebagai warga kelas dua.

\section{J R S (Subjek)}

\begin{tabular}{|l|l|}
\hline Observasi Online & Wawancara Online \\
\hline 24 Juli 11:56 & Sebetulnya sy bergabung bukan atas inisiatif \\
Iklan PT Djarum = & sendiri namun krn di-invite lalu merasa \\
iklan rokok... koq bisa yaa tayang jam $19.00 a n ?$ & $\begin{array}{l}\text { ada manfaatnya untuk mengaktualisasi } \\
\text { informasi ttg pertelevisian. Sebagai orang } \\
\text { yang ada di lingkungan pendidikan wa bil } \\
\text { khusus pada pendidikan ilmu komunikasi } \\
\text { dimana merasa prihatin terhadap fenomena } \\
\text { yang ada yaitu pendangkalan logika generasi } \\
\text { penerus yang dilakukan media TV melalui } \\
\text { tayangan2nya. }\end{array}$ \\
\hline
\end{tabular}

\section{H D (Subjek)}

\begin{tabular}{|l|l|}
\hline Observasi Online & Wawancara Online \\
\hline$\ldots . . . j u s t r u \quad$ memunculkan kecerdasan & Saya berpandangan positif terhadap \\
harus ditumbuhkan lewat pancingan & para perempuan yang berdiskusi di \\
untuk berpikir, bukan dengan menelan yg & grup CNT, meski dari segi jumlah masih \\
gampang-gampang saja. Kesulitan sering & sedikit. Tetapi, apa yang dikemukakannya \\
membuat orang cerdas, kesenangan sering & setidaknya menggunakan pandangan dari \\
membuat orang lena. Kan banyak tuh....yang & sisi perempuan dan itu berharga di tengah \\
belum selesai ditoton, tapi endingnya dah & banyaknya pandangan yang dikemukakan \\
bisa ditebak. & oleh laki-laki. \\
\hline
\end{tabular}

\section{H D (Subjek)}

\begin{tabular}{|c|c|}
\hline Observasi Online & Wawancara Online \\
\hline \begin{tabular}{cc|}
- & $\begin{array}{c}17 \text { Januari 16:25 } \\
\text { Menyaksikan TVOne dan } \\
\text { ILthuif } \\
\text { MetroTV...sungguh dahsyat } \\
\text { banjir yang dialami Jakarta. }\end{array}$ \\
Kemana TVRI kita...? Mana peran TV Publik \\
nya...? Ko adem ayem saja...! Tidak ikut \\
menginformasikan apa yang ingin diketahui \\
Publik
\end{tabular} & $\begin{array}{l}\text { Saya berpandangan positif terhadap } \\
\text { para perempuan yang berdiskusi di } \\
\text { grup CNT, meski dari segi jumlah masih } \\
\text { sedikit. Tetapi, apa yang dikemukakannya } \\
\text { setidaknya menggunakan pandangan dari } \\
\text { sisi perempuan dan itu berharga di tengah } \\
\text { banyaknya pandangan yang dikemukakan } \\
\text { oleh laki-laki. }\end{array}$ \\
\hline
\end{tabular}




\section{ANS (Pengamat Televisi/Anggota KPI Jabar)}

\begin{tabular}{|l|l|}
\hline Observasi Online & Wawancara Online \\
\hline & Isi siaran televisi menurut sejumlah riset masih mewakili \\
nilai umum masyarakat yang menempatkan perempuan \\
sebagai warga kelas di bawah laki-laki. Karena itu, peraturan \\
KPI masih memuat pasal perlindungan perempuan. Sebagai \\
contoh, masih banyak isi siaran yang menggambarkan \\
perempuan sebagai ratu di dapur, teman di atas kasur, atau \\
alat hiburan seksual laki-laki, dan bukan pihak yang setara \\
dengan laki-laki. Saya pribadi tidak bisa berpendapat, apakah \\
nilai masyarakat yang membentuk isi siaran televisi, atau isi \\
siaran televisi yang membentuk nilai masyarakat. Saya pernah \\
menduga, keduanya.
\end{tabular}

Dalam analisis ini, denga kata lain representasi para informan perempuan ini adalah teks berupa ungkapan,-ungkapan, pencitraan, persepsi, dan gambara-gambar yang diperoleh melalui observasi online dan wawancara online. Realitas dan eksistensi perempuan grup FB "Cerdas Nonton Televisi” dibangun atas keterkaitan teks-teks atau wacana-wacana tentang perempuan kaitannya dengan masalah pertelevisian. Sebenarnya banyak perempuan yang dapatberbicaradanmemilikipemikiranyangkonstruktifpadaduniapertelevisian,tapimereka kurang dapat merepresentasikan dirinya dengan baik. Pihak admin (DM) mengatakan bahwa eforum Cerdas Nonton Televisi ini adalah kesempatan perempuan untuk mendekonstruksi dirinya yang dianggap dan diperlakukan closed text tanpa penafsiran sesuai problematikan sosial jamannya, untuk menjadikan dirinya open text. Perempuan dalam wacana "Cerdas Nonton Televisi" ini pun secara langsung dapat mendorong perempuan melek media lainnya untuk bisa menjadi open text sehingga representasi dalam melakukan kritisisme pada televisi yang mereka anggap banyak memiliki sisi negatif dapat lebih jelas terbaca dan terposisikan sesuai keberadaan atau potensinya di wilayah publik maupun privat.

\section{JRS (Subjek)}

\begin{tabular}{|l|l|}
\hline Observasi Online & Wawancara Online \\
\hline $\begin{array}{l}\text { Bila bekerja landasannya mengejar gaji besar } \\
\text { \& popularitas... Lantas dimana peran hati yg } \\
\text { mampu memulyakan derajat manusia sbg } \\
\text { khalifah di muka bumi ini? }\end{array}$ & $\begin{array}{c}\text { Saya ga bisa jawab ini, krn yg tadi } \\
\text { disampaikan kurang concern yang bersuara } \\
\text { itu siapa tapi apa yg disampaikannya. (ini jd } \\
\text { catatan buat sy untuk lbh peduli, tks). }\end{array}$ \\
\hline
\end{tabular}

\section{HD (Subjek)}

\begin{tabular}{|l|r|}
\hline Observasi Online & Wawancara Online \\
\hline & Perempuan yang menjadi anggota CNT adalah perempuan \\
berpendidikan cukup, memiliki kemampuan mengungkapkan \\
ide juga secara baik. Pada satu sisi mereka berharap banyak \\
pada dunia pertelevisian, tetapi di sisi lain mereka sangat \\
khawatir sehingga sangat peka dan mengkritisi apa saja yang \\
terlihat dan terasa atau terpikir kurang pas atau tidak tergali.
\end{tabular}




\section{DM (Admin CNT)}

\begin{tabular}{|l|l|}
\hline Observasi Online & Wawancara Online \\
\hline 18 Februari 21:24 & $\begin{array}{l}\text { Perempuan yang menjadi anggota CNT adalah perempuan } \\
\text { berpendidikan cukup, memiliki kemampuan mengungkapkan } \\
\text { ide juga secara baik. Pada satu sisi mereka berharap banyak } \\
\text { pada dunia pertelevisian, tetapi di sisi lain mereka sangat } \\
\text { khawatir sehingga sangat peka dan mengkritisi apa saja yang } \\
\text { terlihat dan terasa atau terpikir kurang pas atau tidak tergali. }\end{array}$ \\
\hline
\end{tabular}

\section{ANS (Pengamat Televisi/Anggota KPI Jabar)}

\begin{tabular}{|l|l|}
\hline Observasi Online & Wawancara Online \\
\hline KPID sudah banyak & Untuk menyerap dinamika masyarakat yang kritis terhadap isi \\
memberikan sosialisasi & siaran, karena bidang pekerjaan saya di KPID Jabar adalah isi \\
dan peringatan, baik secara & siaran. Saya tidak mengkususkan pada gender/perempuan. \\
forum, media massa, below & \\
the line semisal poster, & \\
banner, forlder, reklame, & \\
dan sebagainya & \\
\hline
\end{tabular}

\section{Pembahasan Penelitian}

Hasil analisis terhadap salah satu media massa baru atau yang David Holmes sebut sebagai second age media yaitu internet khsusus facebook yang memfasilitasi wacana atau diskusi komunitas (khususnya perempuan) di e-forum Cerdas Nonton Televisi yang menjadi fokus penelitian ini, menunjukkan bahwa media ini telah mampu menjadi ruang bagi perempuan untuk berkomunikasi, bersuara, dan berupaya mengarah pada transformasi pemikiran bagi terciptanya reformasi pertelevisian untuk lebih prokhalayak dan mencerdaskan bangsa. Terungkap melalui penelitian ini bahwa komunitas perempuan dalam e-forum CNT ini memang lebih sedikit dibandingkan laki-laki di mana ini sangat memengaruhi wacana yang bergulir di dalamnya. Laki-laki terlihat lebih dominan artinya lebih banyak yang membuat status, melontarkan permasalahan, dan berdiskusi dalam konteks yang lebih serius, intens, dan substansial. Sementara, perempuan agak jarang yang memberi komentar atau membuat status, jika ada hanya sebatas mengikuti status yang telah dibuat laki-laki, ungkapan kata-kata atau kalimat lebih banyak pada pemberian informasi, tanggapan sekilas dan kurang mendalam terhadap persoalan, dan keluh kesah atau uneg-uneg (ini diakui oleh adminnya yaitu DM). Peneliti menilai komentar kedua informan perempuan yang mengisi e-forum CNT sejak 20122013 ini cukup baik, kritis, dan substansinya cukup mengundang pemikiran dan pengkajian. 


\section{SIMPULAN}

Penelitian dengan menggunakan paradigma kritis dengan salah satu variannya yaitu feminist communication theory pada cybercommunity perempuan di e-forum Cerdas Nonton Televisi ini berhasil mengungkap keberadaan wacana atau diskusi perempuan tentang problematika pertelevisian, baik dari sisi konten atau program-program, produksi maupun konsumsi yang mereka nilai sangat merugikan dan tidak mencerdaskan. Selain, itu dalam konteks gender tampaknya peran perempuan sebagai anggota komunitas e-forum CNT yang beranggotakan kurang lebih 3000 ini masih kurang "bersuara", artinya realitas dominasi diskusi atau wacana masih digenggam laki-laki dengan indikasi frekuensi kemunculan status dan komentar masih berada pada pihak laki-laki. Wacana perempuan lebih banyak mengikuti dan sebagai pelengkap.

\section{DAFTAR PUSTAKA}

Littlejohn, W.Stephen.(1996). Theories of Human Communication. Edition VI. New York USA.Wadswoth Publishing Company

Maulana, E. Amalia. (2009.)Consumer Insights via Etnography : Mengungkap Yang tidak Pernah Terungkap. Jakarta. Penerbit Grup Erlangga

Hasan, M. Iqbal. (2002).Pokok-Pokok Materi Metode Penelitian. Jakarta:Ghali Indonesia Neuman, W. Lawrence.(1997).Social Research Methods : Qualitative and Quantitative Approachs. Third Edition. London. Allyn and Bacon

Putra, Nusa, Dr. M.Pd, S.Fil. (2011).Penelitian Kualitatif : Proses dan Aplikasi, Jakarta: PT. Indeks.

Rachman, Budhy Munawar. (1996). "Islam dan Feminisme: Dari Sentralisme ke Kesetaraan" dalam Membingkai Feminisme: Diskursus Gender Perspektif Islam. Jakarta. Penerbit Risalah Gusti

Rakow, F.Lana dan Wackwitz, A. Laura. (2004). Feminist Communication Theory: Selection in Context. USA. SAGE Publication

Suyanto, Bagong dan Sutinah. (200). Metode Penelitian Sosial Berbagai Alternatif Pendekatan. Jakarta: Kencana Prenada Media Grup

Severin, J.Warner dan Tankard,James W.Jr. (2011). Teori Komunikasi : Sejarah Metode, dan Terapan di dalam Media Massa. Jakarta. Penerbit Kencana Prenada Media Grup

Reuneker,Julio. "Persepsi Audience Terhadap Tokoh Ariel Noah Dalam Iklan TVC Vaseline for Men" (Studi Netnografi Ariel Noah Dalam Ikaln Vaseline Man)" .e-journal.uajy. ac.edu. Diakses 15 Setember 2014. http://www.academia.edu

Muhlishah, Widatul. "Perbedaan Interaksi Antara Anggota Laki-Laki dan Perempuan Dalam Diskusi Online (Studi Netnografi pada Situs DetikForum)".Jurnal interaktiffisippub. blogspot.com. Diakses 18 Desember 2011. http://www.academia.edu 
